\title{
Awareness and Reason towards Slow Adoption of E-Payment System: Study of Hyderabad
}

\author{
Pireh Panhwer*, Adnan Pitafi, Muhammad Saad Memon and Anum Memon \\ Mehran University of Engineering and Technology (MUET), Jamshoro, Sindh, Pakistan \\ pireh.panhwer@hotmail.com; adnanpitafi@gmail.com; saad.memon@faculty.muet.edu.pk; 13sw25@gmail.com \\ *Correspondence: pireh.panhwer@hotmail.com
}

Received: 10 ${ }^{\text {th }}$ October 2019; Accepted: $14^{\text {th }}$ January 2020; Published: $1^{\text {st }}$ February 2020

Abstract: E-payment is a convenient and easy mode of payment, due to its convenience it makes everyone's life easy, because it takes less time to make transaction. This makes a solid case for adoption in many developed as well as developing countries. However, there are many countries who have not successfully implemented it due to lack of facilities and even lack of awareness of customers. Even in a developing country like Pakistan E-Payment system is not so popular because of many operational constraints, according to Asian Development Bank (ADB) almost 95\% people of Pakistan rely on case on delivery (COD) method and only 5\% people use E-Payment system. In Hyderabad many people prefer COD method when they order online. This research aimed to analyze the customer awareness and lack of adoption of E-payment system in Hyderabad marketplace. The survey was conducted using questionnaire that was adopted from existing measurement instruments from past research papers. The questionnaires were distributed to customers and banks of Hyderabad, male and female, aged ranging from 18 to 51 years old. The data is analyzed using SPSS Software. The sample size was 350 respondents of Hyderabad. This study found that system credibility, facilitating conditions, perceived ease of use and perceived usefulness are the most important factors that affect to the customer awareness and slow adoption of E-payment system. This research will help to understand the reason behind lack of adoption of E-Payment system by studying the customer's knowledge about the usage of E-payment system and evaluate the reason behind this slow adoption of customers.

Keywords: Technology Awareness; Technology Adoption; UTAUT model; TAM model; E-payment

\section{Introduction}

The internet users have been growing day by day. As the number of internet users increases so ecommerce is growing as well. Generally a payment is a transfer of an item of value from one party to another in exchange for the provision of goods, services or both, or to fulfill a legal obligation-payment is method or way of transferring money from buyer to seller or from one party to another electronically without the use of paper or cheques (Rachna, 2013). E-payment is method or way of transferring money from buyer to seller or from one party to another electronically without the use of paper or cheques (Rachna, 2013). Over the course of history the payment system has evolved significantly, from the simplest and oldest form of payment, which is the exchange of one good or service for another to present day Emoney and the Electronic payment system URS (2015). The electronic commerce and electronic payment system of one country may be different from other country because different countries have different IT

Pireh Panhwer, Adnan Pitafi, Muhammad Saad Memon and Anum Memon, "Awareness and Reason towards Slow Adoption of EPayment System: Study of Hyderabad", Annals of Contemporary Developments in Management \& HR (ACDMHR), Print ISSN: 2632-7686, Online ISSN: 2632-7694, pp. 6-21, Vol. 2, No. 1, $1^{\text {st }}$ February 2020, Published by International Association of Educators and Researchers (IAER), DOI: 10.33166/ACDMHR.2020.01.002, Available: http://acdmhr.theiaer.org/archive/v2/v2n1/p2.html. 
infrastructure and culture. So when customers do shopping or make transactions on e-commerce sites by e-payment system so it is important to identify the factors that affect customers. People usually use traditional methods for transaction of money but e-payment system allows people to make transactions electronically when purchasing something. E-payment system has provided many choices and convenience to the customers.

Globally e-payment system faces many challenges. Today many people use e-payment systems for online purchasing, instead of using check or cash by World Economic Forum network (2018).Nowadays almost 95 percent population of Pakistan makes online purchasing through cash on delivery method says a report launched jointly by the Asian Development Bank (ADB) and the United Nations Economic and Social Commission for Asia and the Pacific.

This study uses two theories TAM and UTAUT model for analyzing that what are the constraints or reason in adoption of E-Payment system. In Hyderabad, many people prefer the COD method when they order online. This research aimed to analyze customer awareness and the lack of adoption of the E-payment system in the Hyderabad marketplace. To measure how much people in Hyderabad know about the Epayment system and how much they use the E-payment in their day to day transactions. So, TAM and UTAUT model is used for identifying slow adoption of E-payment system in people of Hyderabad to know that what is the main constrains or reasons in adoption of E-payment system.

\subsection{Current Situation of E-Payment in Pakistan}

E-payments in Pakistan is an evolving concept that intends to provide a basket of the solutions to its citizens and in fact, it is rapidly gaining momentum in Pakistan, but still more than half of the population do not access E-payment system and cash is still a dominant payment method as it is considered safe by almost all the retailers and suppliers.

Talking specifically about Pakistan, according to World Bank, about 100 million adults in Pakistan don't have access to formal and regulated financial services. This number is approximately $5 \%$ of the world's entire "unbanked "population, which currently stands at 2 billion, report by IndraStra Global Editorial Team (2018).

So, there is a problem in adopting E-payment system in Pakistan because people are not very much aware of it and there are some operational constraints in adoption of E-payment in Pakistan.

\subsection{Objectives}

This research study was exploratory in nature and is an attempt to analyze the awareness of EPayment system in people of Hyderabad, recognize \& investigate reasons impacting the usage of EPayment in Hyderabad.

\section{Literature Review}

\subsection{E-Payment}

Generally, payment is simply a money or cash that is transferred from buyer to seller when buyer has purchased something. E-payment is method or way of transferring money from buyer to seller or from one party to another electronically without the use of paper or cheques. People usually use traditional methods for transaction of money, but e-payment system allows people to make transactions electronically when purchasing something from e-commerce sites.

For developing countries many researchers have focused on EPS (Electronic Payment System). Peter M Ogedebe with his colleagues worked on an EPS, identifies some issues of e-payment system regarding customer and merchant's point of view and providing security for users. (Tsiakis, 2005) plans to distinguish the difficulties of electronic payment system and offer a few answers for enhance the e-payment framework 
quality. The focus of J. Raja, M. S. Velmurgan, and A. Seetharaman (2008) is to recognize and clarify distinctive techniques for e-payments and the authors analyze the difficulties of electronic payments from alternate point of view and give starter security countermeasures to every one of the issues. Dennis Abrazhevich (2004) analyzes that electronic payment systems are necessary parts of e-commerce. AhmadReza Sadeghi and Markus Schneider (1990) argued. E-payment should be capable when you make transactions globally so you can easily make transactions. Daniel and Sathye (1999) concluded that with the advancement of e-payment framework/channels, people and organizations, would now be able to ask for information and do most retail saving money administrations by means of the computer utilizing the web access, cell phone, computerized teller machine, and so on. Gary and Perry (2002) averred that epayment has an overriding advantage over the traditional payment system, such as authority, speed, privacy, convenience, good acceptability, low transaction cost, good acceptability, authority, anonymity, interoperability, security, universality, etc.

(Rachna, 2013) analyze some of the challenges and solutions of e-payment systems, risks to the epayments are exposure of user's personal information, stealing of money etc.

E-payment system is easy and convenient means you do not need to take load of money with you every time says Sujith T S, Julie C D (2015).

(URS, 2015) concluded that one of the technological innovations are e-payment system although it has many benefits of using e-payment system like providing fast and easy transaction process but with this it is risky as well like security issues.

\subsection{Types of E-Payment Systems}

E-payment gives a platform by which the transactions can be made without cash or paper. As the Epayment system has reduces the use of paper money or checkbooks. The electronic-payment systems has many types like electronic cash(e-cash), electronic wallet(e-wallet), debit cards, credit cards, digital accumulating balance and smartcards.

\subsubsection{Credit Card}

A credit card is a plastic money that is used for buying goods or services. In a credit card there is unique number embedded that is actually ID card number for user. Credit card has expiry date as well, when user want to buy something so simply, he/she can enter their card number and buy that product and then seller check the details and be confident of payment.

\subsubsection{Debit Card}

A Debit card is like ATM card and it can be used at ATM. A debit card is a digital version of checkbooks. It is connected to user's bank account. In debit card when user make transactions so amount would be withdrawing from their bank accounts. And you can use it in restaurants, retail stores or for online shopping.

\subsubsection{E-Wallets}

Electronic wallet (e-wallet) is simply like a moneybag. E-wallet is used for storing user's data like user's card numbers, its name, contact details means all the information of user that is used by user when he/she is checking up the different electronic sites. E-wallets are very effective because in this, users just need to enter its information only once and when user again shop or access to any other site, so it doesn't need to enter its data again and easily execute any website.

\subsubsection{E-Cash}

Electronic cash (E-cash) is an online payment method in which customers are given a unique token and that token has been verified, means when customer want to purchase something electronically so 
he/she must have a credit or debit card and enter token number that is given to them and at the merchant site, merchant have to confirm about that token number and get money from customers account.

\subsubsection{Digital Accumulating Balance System}

The digital accumulation balance system is an approach which makes the customer life easy. As through this system the customers can buy the products online or they can also pay the bills. The balance is deducted from the customer bank account at the end of month just like the utility bills that are paid at the end of the month. It is also suitable for the micro payments that include small products that customer buy, and their prices are of low cost. The telecommunication companies have extensively adopted this system.

\subsubsection{Smart Card}

It is a thin, credit card sized piece of plastic which contains a half-inch-square area that serves as the card's input-output system. A smart card contains a programmable chip, a combination of RAM and ROM storage and can be refilled by connecting to the bank. It is known as smart card because the ability of chip to store the information in its memory makes the card smart.

\subsection{Unified Theory of Acceptance and Use of Technology (UTAUT) Model}

As there is instantaneous change and expansion in internet and electronic business, so it is to identify that how financial institutes like banks manage their business and what is its impact on their business (Lee, 2009). A while ago, people have no options and they can only make transactions through traditional way or by ATM but now as there are many choices for people so they make transactions for anything at any time and at any location, because nowadays internet banking make their way of transaction more easy (AbuShanab P. J., 2010). Now customers can perform their other basic functions, for example, financial exchanging reserves, records data, paying bills and using speculation and check benefits through bank sites (Hanafizadeh et al., 2014).

There are many models and theories have been developed to clarify the connection between user attitudes, beliefs and behavioral intensions (BI) to use the innovation. From the flood of social brain psychology, innovation diffusion theory (IDT), theory of planned behavior (TPB), the social psychological theory, technology acceptance models (TAM) are just a couple of the major measured methodologies that have lead the way /in analyses and results(Yietal.,2006;Venkateshetal.,2012;Yousafzai, 2012). A survey and blend of these models of innovation use brought about the bound together hypothesis of acknowledgment and utilization of innovation (UTAUT) (Venkatesh, 2003).

The UTAUT theory consists of four constructs (social influence, performance expectancy, effort expectancy, facilitating conditions) are the factors of behavior and behavioral intension and these constructs are examined by age, experience, willingness of use and gender (Venkatesh, 2003).

\subsubsection{Social influence}

This defines that users can be influence from its surroundings. It is the change in behavior of one user that is influenced from another user intentionally or unintentionally

\subsubsection{Performance Expectancy}

This defines that technology should be of that type that improves performance or by which user can easily accomplished its task.

\subsubsection{Effort expectancy}

This defines that technology should be of that type or feasible that customer can easily use it or it is a belief that technology is effortless. 


\subsubsection{Facilitating Conditions}

This defines all the factors that supported technology and enhance its performance. This defines that technical infrastructure supports the use of system (Venkatesh, 2003).

By examining all these factors in real world, experts and scholars then identify the person's aim to use a system, and by this they are allowed to identify the key influences on the acceptance of technology. The theory was developed through the review and integration of eight dominant theories and models, namely: the Theory of Reasoned Action (TRA), the Technology Acceptance Model (TAM), the Motivational Model, the Theory of Planned Behavior (TPB), a combined TBP/TAM, the Model of PC Utilization, Innovation Diffusion Theory (IDT), and Social Cognitive Theory (SCT). These all models and theories have been used successfully in past by many scholars and researchers for the purpose of technology adoption and innovation in many fields like marketing, management, information system and social psychology etc. In their original article, Venkateshetal presented results from a six-month study of four organizations, which revealed that the eight contributing models explained between 17 and 53 per cent of variance in user intentions to use IT. Brought together Unified Theory of Acceptance and Use of Technology (UTAUT) is valid to be used in considering the utilization of e-payment system among the shoppers and customers.

\subsection{Technology Acceptance Model (TAM)}

This research used Technology Acceptance Model, because TAM is frequently used to explore user's behavior intension of technology usage. The concept of Technology Acceptance Model (TAM) was given by Davis to give clear assumptions of customer acceptance. It is capable of clarifying user behavior over a wide scope of end-user computing technologies and client population hypothetically justified (Davis, 1989;1993). TAM depends on following core components:

\subsubsection{Perceived Usefulness}

This defines user's perception regarding the usage of technology like computer by which he/she can improve its performance and achieve its goal.

\subsubsection{Perceived Ease of Use}

This defines user's perception regarding effortlessness of a technology like computer system. And when user feels comfort in using technology, so it directly relates to its acceptance of technology.

Technology Acceptance Model (TAM) is derived from Theory of Reasoned Action (TRA) model that was developed by Fishbein and Ajzen, and it explains user's behavior or attitude based on the situation and it is combination of personal beliefs and attitudes and their effects to the individual. The main concept of TRA is that if everyone thinks that by adopting the technology positive results would achieve so everyone easily adopts the technology (Compeau \& Higgins, 1995).

Technology Acceptance Model (TAM) has been broadly used to measure the attitude of user's towards using or adopting the technology from different areas. So, this means that TAM is used for measuring user's attitude or behavior towards different IT based services (Ahmed, Zin \& Majid, 2016).

So many researches have confirmed the TAM is beneficial or being helpful as a tool for exploring and identifying user information technology (Taylor and Todd, 1995), (Geffen \& Straub, 2000); (Doll et al, 1998).

So in order to perform research, we proceed to TAM approach and ideas, and used a modified TAM model, as proposed by (Money 2004), So as to define connection between perceived ease of use , perceived usability and user's goal to use of the new payment service.

In many developing countries E-Payment system it is commonly use but in most of the countries EPayment system is still not popular and at its initial stage. In a country like Pakistan that is actually constructing and enhancing its IT infrastructure. Although E-banking acceptance studies have been directed in many developed and Western countries, studies for a developing country such as Pakistan remain few. 
As examined by Cai (2008) that in the recent years many researchers have found that users are aware about the advantages of E-Payment system such as flexibility, compatibility, ease, time saving and dependability of all of which are very important in approval of E-Payment system. In a study by Ankit (2011), he revealed that as much as adoption of internet banking is concerned, the factors such as security, trust and privacy have been stated as the most imperative ones for a consumer. It does not mean that the rest of the factors such as perceived usefulness and user acceptability are not as important.

A study by Davis (2010) explained that perceived usefulness is a factor to which an individual believes that using a certain kind of structure will augment his or her enactment. It is a person's belief about the usefulness of something and it determines his/her willingness to use it to fulfill their purpose. The research conducted by Cai (2008) suggested that clients of E-banking are more prone to analyze rewards of the facilities (e.g., practicality, comfort, info) as compared to the client who are not using E-Banking and consider all the disadvantages of it. This suggests that the already existing users may have a better idea about the usefulness of E-banking unlike the people who don't use it and they might have reservations when it comes to making online transactions. Researcher EM (1983) believed that perceived usefulness is an aspect that explains the point to which the invention is considered not problematic to comprehend, absorb or put into function. User acceptability of E-banking may rely on the fact that how much they believe that internet banking can save their time, money and how secure and efficient it is. Ease of use remains an important factor here. A study by Davis (2010) explained that perceived usefulness is a factor to which an individual believes that using a certain kind of structure will augment his or her enactment. It is a person's belief about the usefulness of something and it determines his/her willingness to use it to fulfill their purpose. The research conducted by Cai (2008) suggested that clients of E-banking are more prone to analyze rewards of the facilities (e.g., practicality, comfort, info) as compared to the client who are not using E-Banking and consider all the disadvantages of it. This suggests that the already existing users may have a better idea about the usefulness of E-banking unlike the people who don't use it and they might have reservations when it comes to making online transactions. Researcher EM (1983) believed that perceived usefulness is an aspect that explains the point to which the invention is considered not problematic to comprehend, absorb or put into function. User acceptability of E-banking may rely on the fact that how much they believe that internet banking can save their time, money and how secure and efficient it is. Ease of use remains an important factor here.

\section{Conceptual Framework}

The following diagram demonstrates the conceptual framework of research.

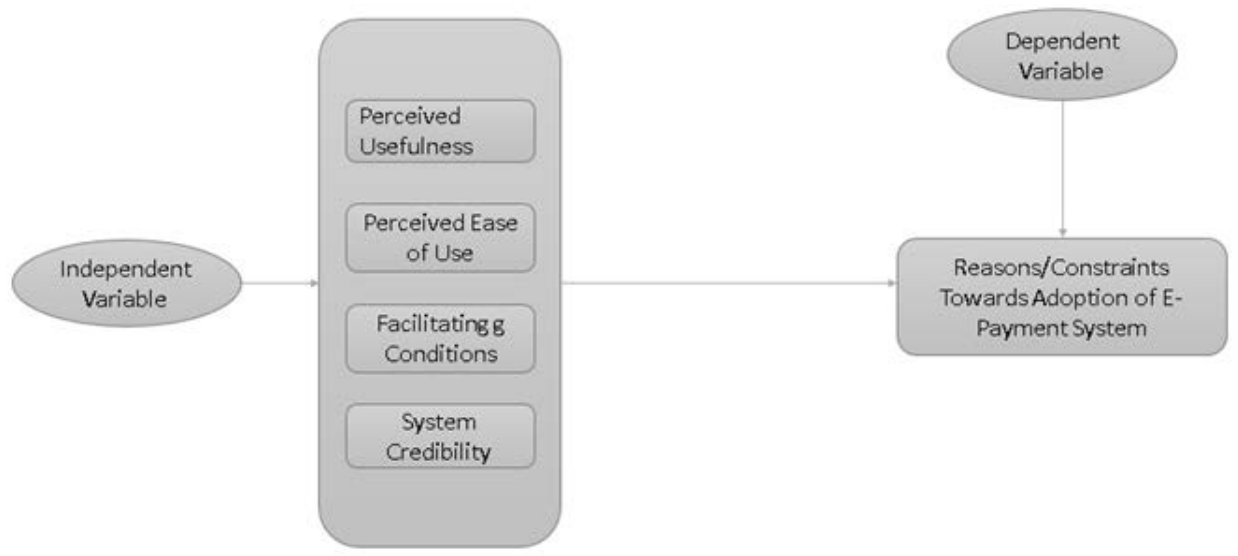

Figure 1. Conceptual Framework

This study defines major constraints in adoption of E-Payment system are Perceived Usefulness, Perceived Ease of Use, Facilitating Conditions and system credibility. The first three reasons or constraints 
are identified from UTAUT and TAM model and last constraint System credibility is another constraint that affect customer's adoption of E-Payment system. This study has dependent as well independent variables. Perceived Usefulness, Perceived Ease of Use, Facilitating Conditions and System credibility are independent variables whereas Users adoption of E-Payment system is dependent variable.

\subsection{Hypothesis}

H1: Perceived usefulness has positive and moderate relationship with User's adoption of E-Payment system.

H2: Perceived ease of use has positive and significant relationship with User's adoption of E-Payment system.

H3: Facilitating conditions has positive and moderate relationship with User's adoption of E-Payment system.

H4: System credibility has positive and significant relationship with User's adoption of E-Payment system.

\section{Research Methodology}

Pakistan is a developing country where the use of E-Payment system is not so popular due to various reasons. If E-Payment system is not so popular in Pakistan, then in city like Hyderabad it is obvious that E-Payment system doesn't get much popularity so we are going to examine what are the factors that affects the usage of E-Payment system. From above literature, four factors are identified, which are Perceived usefulness, Perceived ease of use, Facilitating conditions, and System credibility. For analyzing customer awareness and what reasons or factors that affects customer's usage of E-Payment system, a questionnaire was developed and modified after extensive literature.

\subsection{Nature of the Study}

A descriptive as well as predictive study is undertaken to analyze the awareness of E-Payment system and examine the factors affecting the usage of E-Payment system in Hyderabad. This research is hypothesis causal study showing a cause and effect relationship between the variables. Data is collected regarding the usage of E-banking. The relationship predicted through factor identification and their strength direction and magnitude is measured.

\subsection{Population}

The population for this study is all customers and some banks of Hyderabad Pakistan.

\subsection{Tools and Techniques}

To analyze the data collected statistical methods are used. Descriptive and inferential statistics involving Correlation and Regression are focused on. Correlation will help us identify the strength of the relationship of the variables while regression will measure the magnitude of their relationship. Statistical Package for Social Sciences was used to analyze data.

\section{Results and Discussion}

\subsection{Demographic Statistics}

Among the sample of 306 people, 163 are male and 143 are female. The overall percentage of the male is $53.3 \%$ and women are $46.7 \%$ as shown in the table 1 . 
Table 1. Gender of the Person

\begin{tabular}{|ll|r|r|r|r|}
\hline & Frequency & Percent & Valid Percent & Cumulative Percent \\
\hline \multirow{4}{*}{ Valid } & Male & 163 & 53.3 & 53.3 & 53.3 \\
& Female & 143 & 46.7 & 46.7 & 100.0 \\
& Total & 306 & 100.0 & 100.0 & \\
\hline
\end{tabular}

Refer Table 2.Among the sample of 306 people 20 people with age $<18,165$ are between the ages 19-25 which is $53.9 \%, 77$ people are between the ages of 26-33which is $25.2 \%, 23$ people are between the ages of $34-41$ which is $7.5 \%, 15$ people are between the ages of $42-50$ which is $4.9 \%$ and 6 people are the ages of $51>$ which is $2.0 \%$ of the total sample size.

Table 2: Age of the Person

\begin{tabular}{|c|c|c|c|c|c|}
\hline & & Frequency & Percent & Valid Percent & Cumulative Percent \\
\hline \multirow{7}{*}{ Valid } & $<18$ & 20 & 6.5 & 6.5 & 6.5 \\
\hline & $19-25$ & 165 & 53.9 & 53.9 & 60.5 \\
\hline & $26-33$ & 77 & 25.2 & 25.2 & 85.6 \\
\hline & $34-41$ & 23 & 7.5 & 7.5 & 93.1 \\
\hline & $42-50$ & 15 & 4.9 & 4.9 & 98.0 \\
\hline & $51>$ & 6 & 2.0 & 2.0 & 100.0 \\
\hline & Total & 306 & 100.0 & 100.0 & \\
\hline
\end{tabular}

Refer Table 3. The Associate Degree (BA/BSc) holders among the sample of 306 people are 35 which is $11.4 \%$. The number of customers of BBA/BE/MBBS/BS holder's are136 which is $44.4 \%$ of the total sample size. The number of customers of MBA/ME/FCPS/MS holders are 78 which are $25.5 \%$ of the total population. The number of customers of PHD holders are 9 which is $2.9 \%$ of the total sample size. And number of customers who owned other level of education are 48 which is $15.7 \%$ of the total sample size.

Table 3: Qualification of the Person

\begin{tabular}{|ll|r|r|r|r|}
\hline & Frequency & Percent & Valid Percent & Cumulative Percent \\
\hline \multirow{2}{*}{ Associate Degree (BA/BSc) } & 35 & 11.4 & 11.4 & 11.4 \\
VBalid & 136 & 44.4 & 44.4 & 55.9 \\
& MBA/ME/MBBS/BS & 78 & 25.5 & 25.5 & 81.4 \\
& PHD & 9 & 2.9 & 2.9 & 84.3 \\
& Specify any other & 48 & 15.7 & 15.7 & 100.0 \\
Total & 306 & 100.0 & 100.0 & \\
\hline
\end{tabular}

Refer Table 4. Among the sample size of 306, 155 are the students with 50.7\% ,117 are the Employed with $38.2 \%, 16$ are Not-employed with 5.2\%,9 are Self-employed with $2.9 \%$, and 9 are Housewives with $2.9 \%$.

Table 4: Occupation Status of the Person

\begin{tabular}{|ll|r|r|r|r|}
\hline & Frequency & Percent & Valid Percent & Cumulative Percent \\
\hline \multirow{3}{*}{ Valid } & 155 & 50.7 & 50.7 & 50.7 \\
& Etudent & 117 & 38.2 & 38.2 & 88.9 \\
& Not employed & 16 & 5.2 & 5.2 & 94.1 \\
& Self-employed & 9 & 2.9 & 2.9 & 97.1 \\
& Housewife & 9 & 2.9 & 2.9 & 100.0 \\
Total & 306 & 100.0 & 100.0 & \\
\hline
\end{tabular}

Refer Table 5. Respondent's income $<15000$ and below in a sample of 306 is 59 which is $19.7 \%$. 100 people have income between 16,000-45,000 which is 33.4\%. 54 people have income $46,000-75,000$ which is $18.1 \%$. 39 people have income $76,000-105,000$ which is $13.0 \% .13$ people have income $106,000-135,000$ 
which is $4.3 \% .10$ people have income $136,000-150,000$ which is $3.3 \%$ and 24 people have income above 150,000 which is $8.0 \%$ of the total sample size.

Table 5. Income of the Person

\begin{tabular}{|ll|r|r|r|r|}
\hline & Frequency & Percent & Valid Percent & Cumulative Percent \\
\hline & $<15000$ and below & 59 & 19.3 & 19.7 & 19.7 \\
& $16,000-45,000$ & 100 & 32.7 & 33.4 & 53.2 \\
& $46,000-75,000$ & 54 & 17.6 & 18.1 & 71.2 \\
Valid & $76,000-105,000$ & 39 & 12.7 & 13.0 & 84.3 \\
& $106,000-135,000$ & 13 & 4.2 & 4.3 & 88.6 \\
& $136,000-150,000$ & 10 & 3.3 & 3.3 & 92.0 \\
& and above & 24 & 7.8 & 8.0 & 100.0 \\
& Total & 299 & 97.7 & 100.0 & \\
Missing & System & 7 & 2.3 & & \\
Total & & 306 & 100.0 & & \\
\hline
\end{tabular}

\subsection{Customer Awareness of E-Payment System}

Based upon the collected data by questionnaire and after applying descriptive statistics we found the following results:

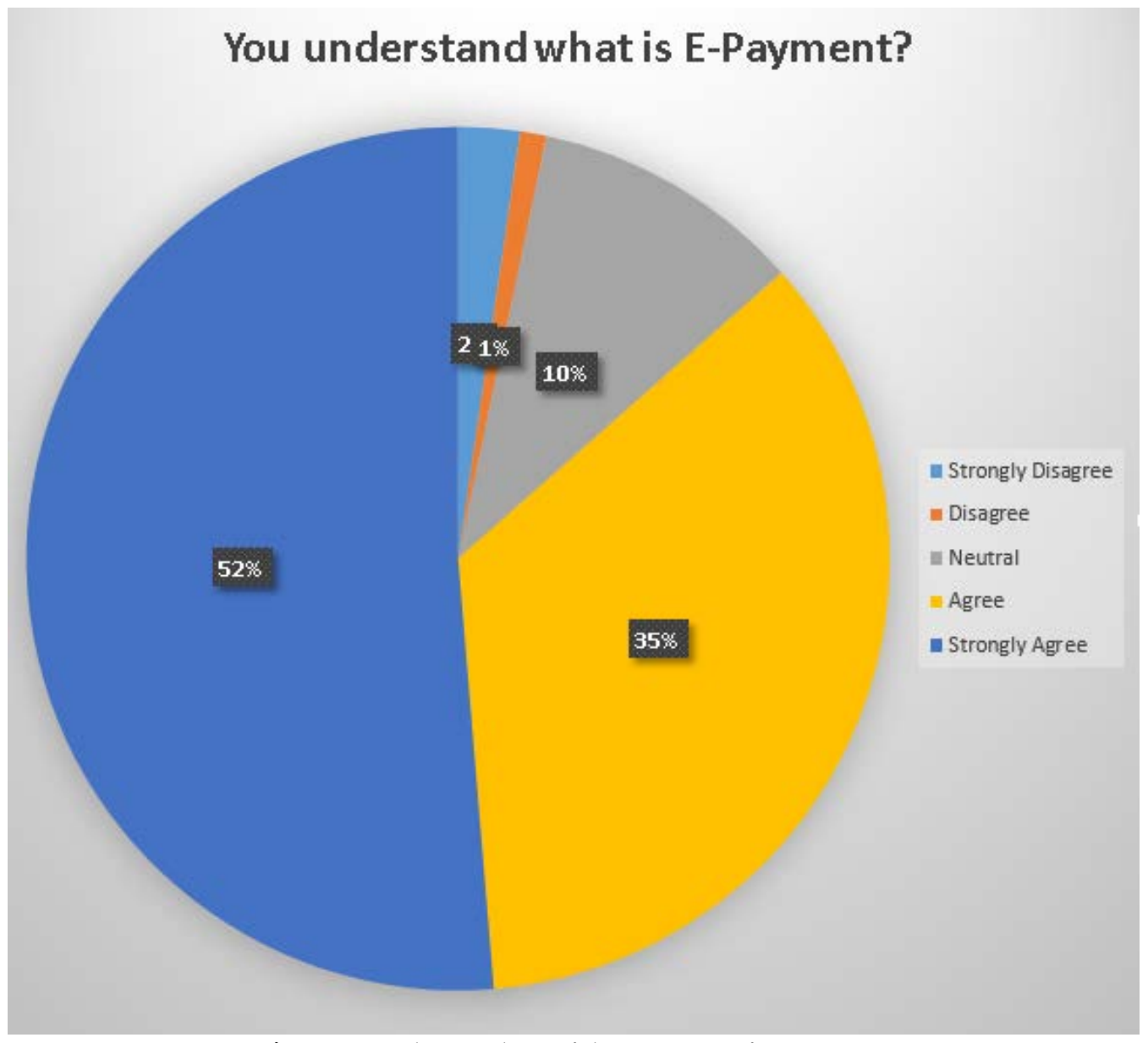

Figure 2. Understanding of the Concept of E-Payment

By Collecting data from customers of Hyderabad the result shows that $52 \%$ people are well known about E-Payment System. 


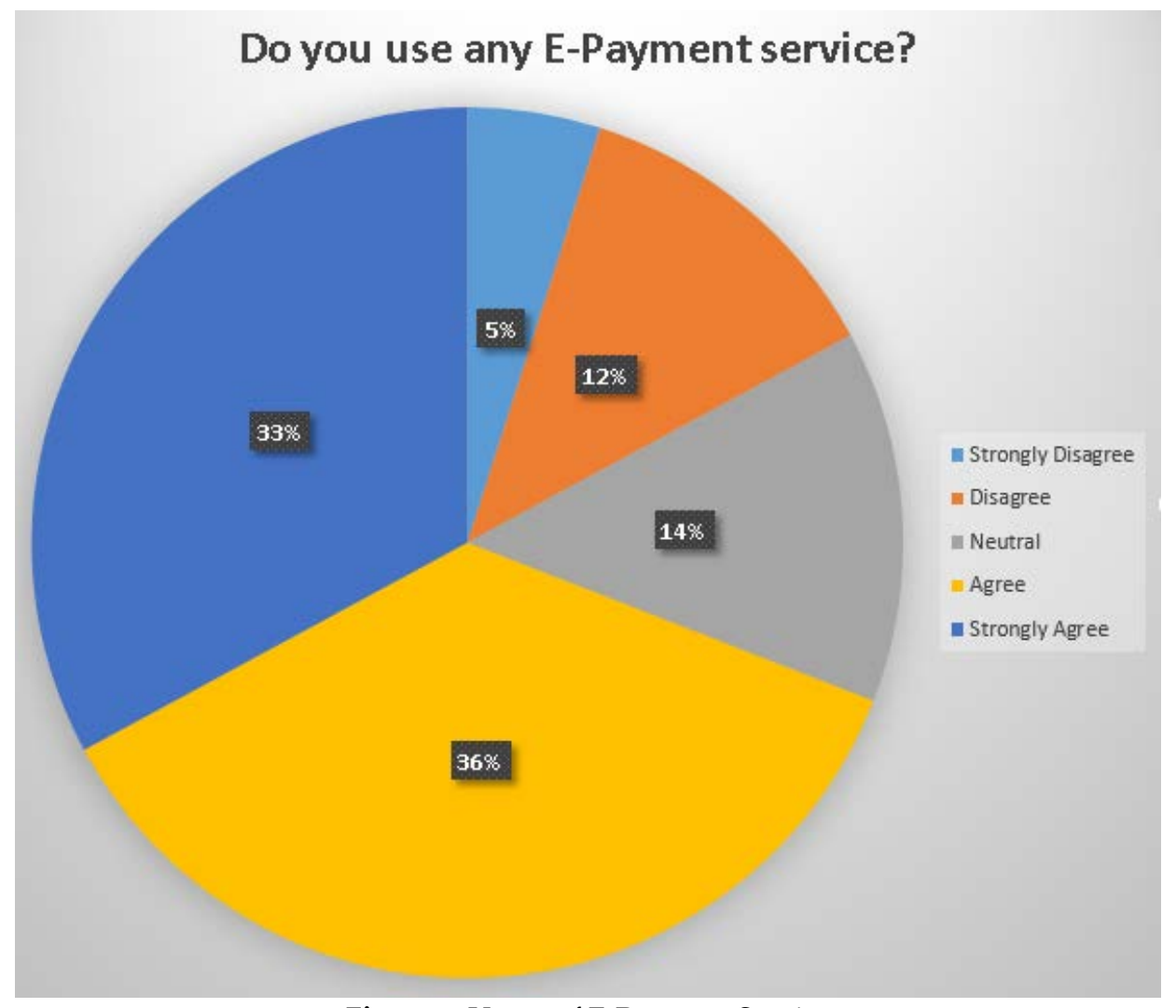

Figure 3. Usage of E-Payment Service

Results show that $36 \%$ people uses E-Payment System.

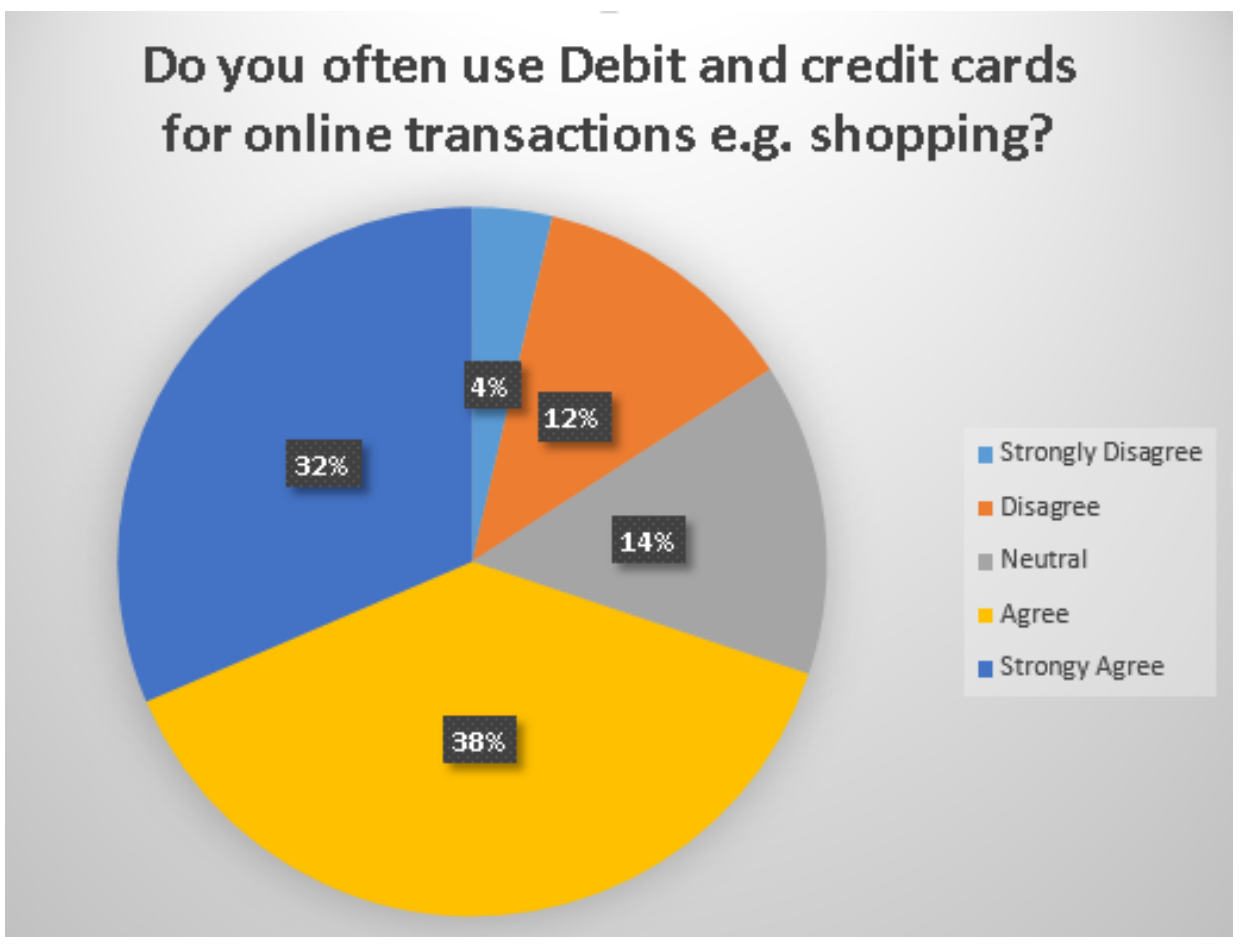

Figure 4. Frequency of Using Debit/Credit Cards

Results show that $38 \%$ people use debit credit cards. 


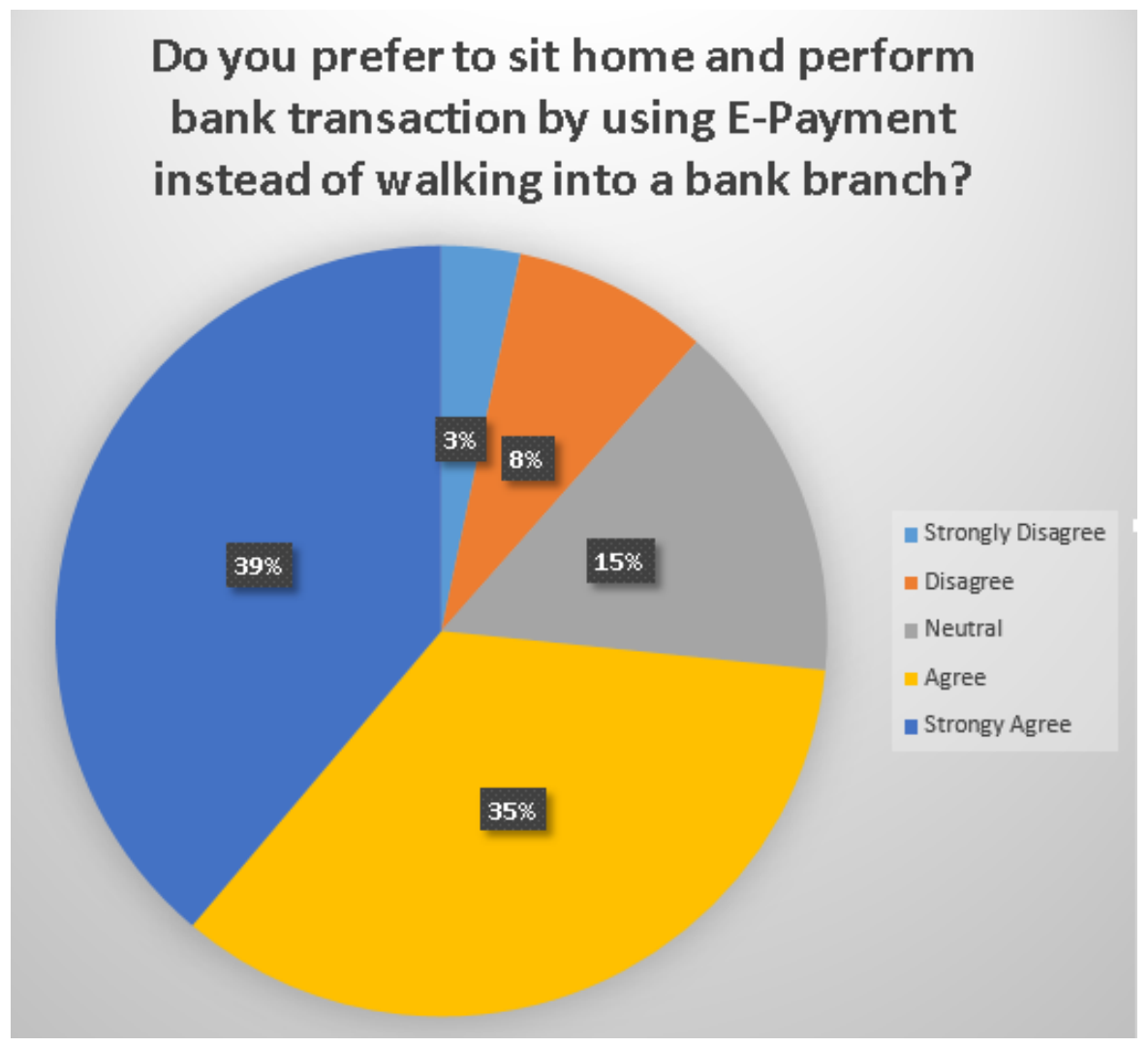

Figure 5. Preference of Using E-Payment

Results show that $35 \%$ People prefer to sit home and perform bank transaction by using e-payment instead of walking into a bank branch.

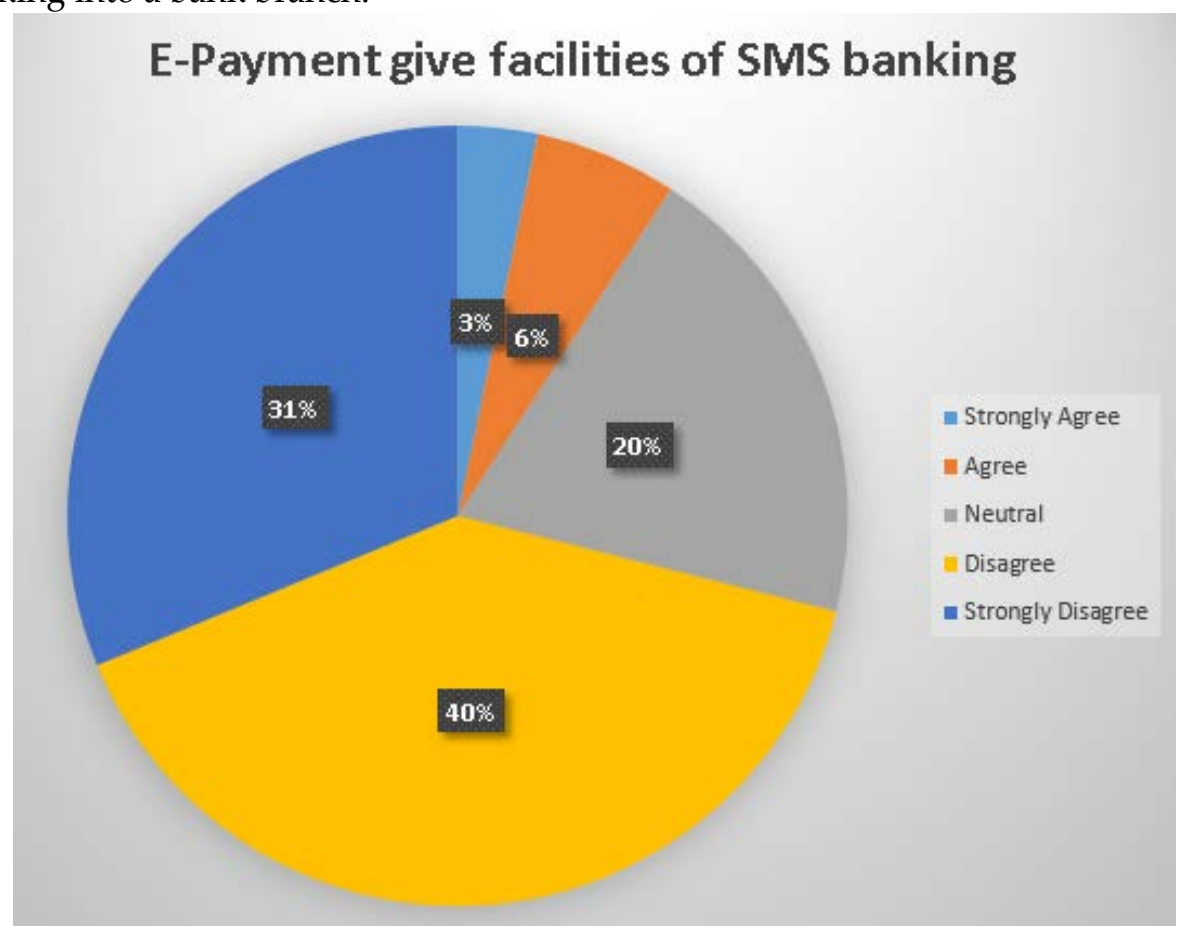

Figure 6. View About E-Payment Facilities

Results show that $40 \%$ People agreed that E-Payment system gives facility of SMS banking. 


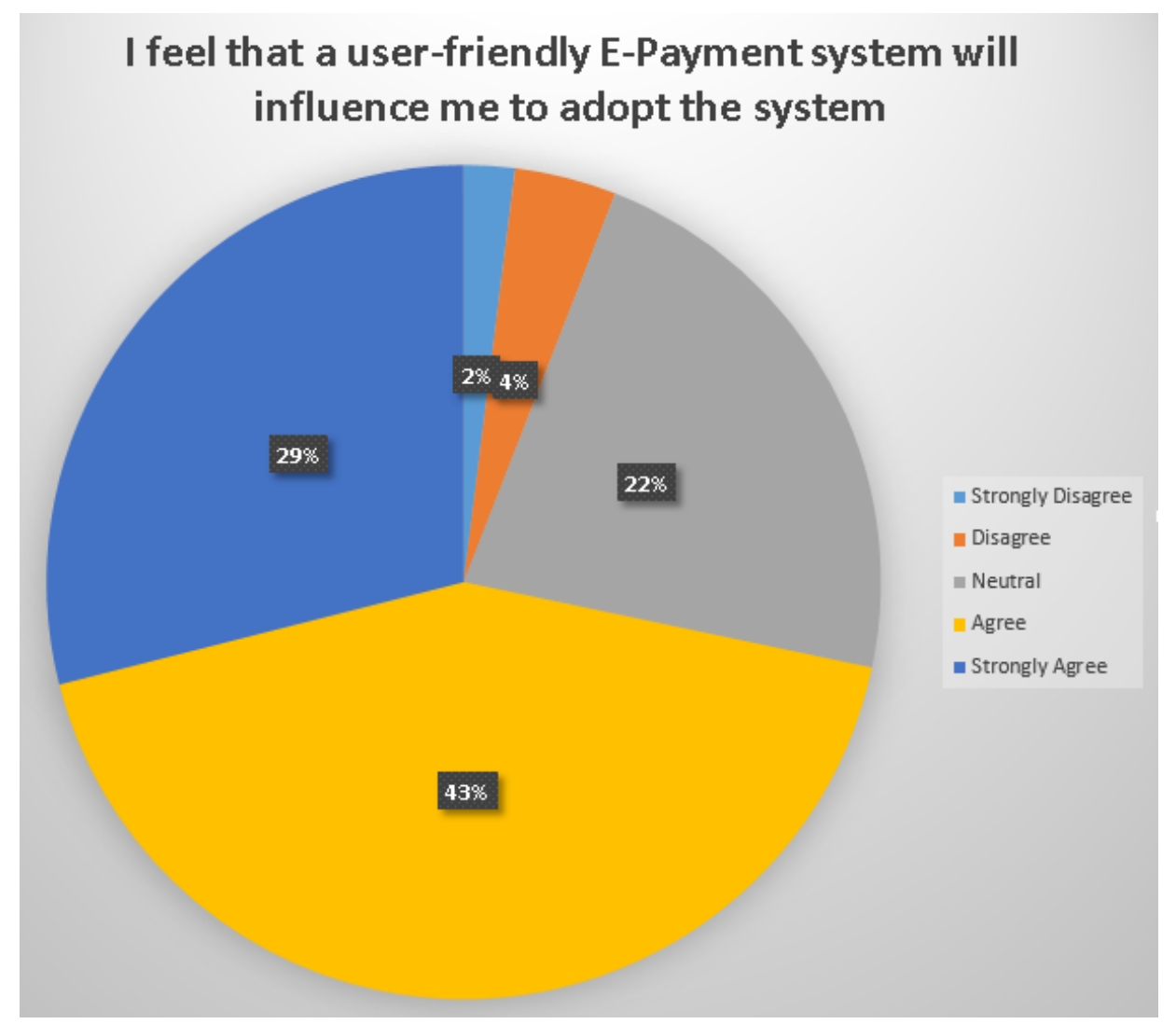

Figure 7. View About Friendliness of E-Payment System

Results show that $43 \%$ people feels that E-Payment system is user friendly.

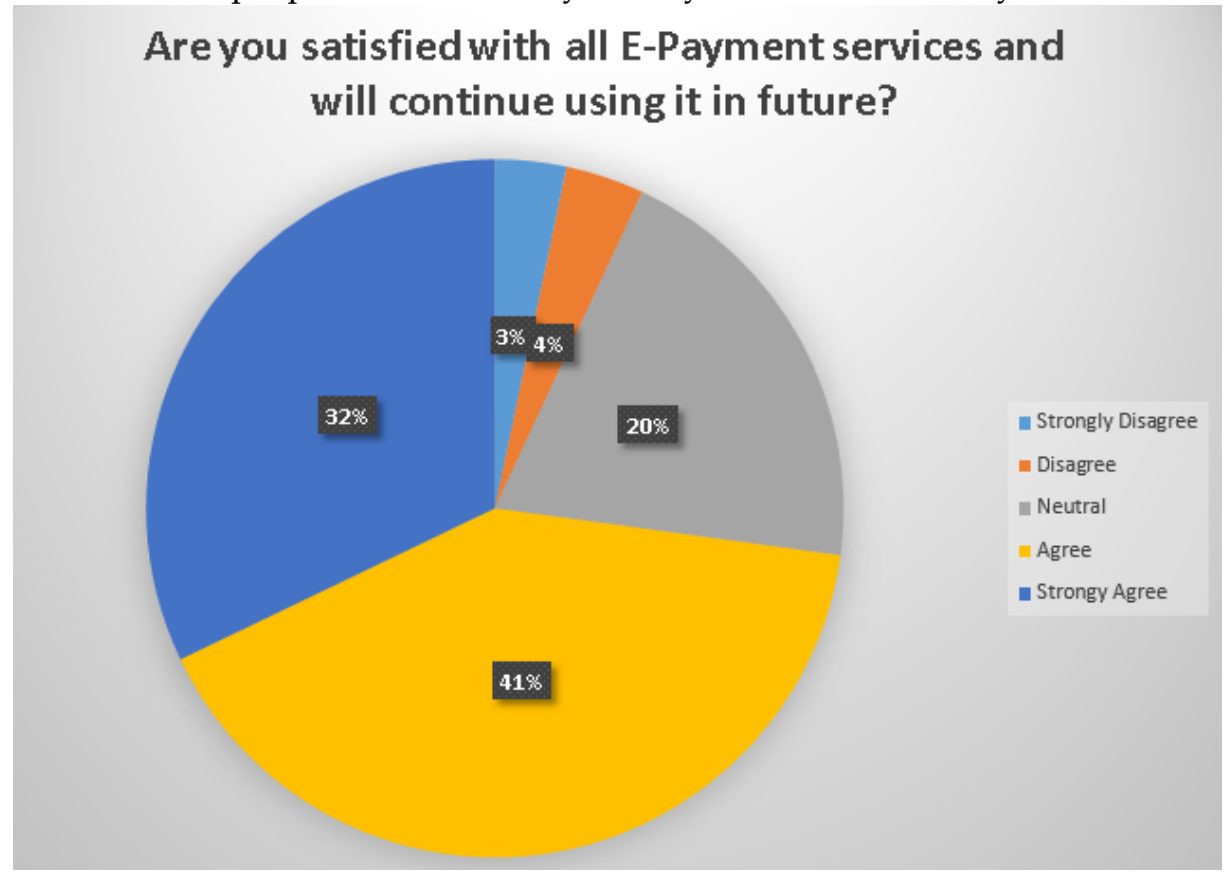

Figure 8. Satisfaction with E-Payment Service

Results show that $41 \%$ people are satisfied with E-Payment System. So All the results of Awareness show that most of the people of Hyderabad are known to E-Payment system. 


\subsection{Descriptive Statistics}

Table 6. Descriptive statistics

\begin{tabular}{|l|c|c|c|}
\hline & $\mathrm{N}$ & Mean & Std. Deviation \\
\hline System_Credebility & 254 & 2.1891 & .66542 \\
Percieved_Ease_Of_Use & 254 & 2.0394 & .74847 \\
Facilitating_Conditions & 254 & 2.3241 & .72949 \\
Percieved_Usefulness & 282 & 2.0523 & .75997 \\
User_Adoption & 282 & 2.1371 & .83429 \\
Valid N (listwise) & 254 & & \\
\hline
\end{tabular}

Refer Table 6. These are the results of analysis of the variables. The number of observations is the total of $\mathrm{N}$ and the number of missing values. The total number of respondents is 306 who were asked to fill the questionnaire. The table shows the descriptive statistics of the data. Likert scale was used to answer the questions.

The mean statistic identifies the answer of most of the respondents on average. The mean answer for System Credibility is 2.1891, for Perceived Ease of Use is 2.0394, for Facilitating Conditions is 2.3241, for Perceived Usefulness is 2.0523, and for User Adoption is 2.1371.The answer for all variables was almost near 2.3. This means that most of the answers were "Average" on the likert scale.

Standard deviation statistic measures the spread out of the data. Greater number in Standard Deviation means more wide spread data. The lowest standard deviation is for System Credibility of 0.66542and the highest standard deviation is for User Adoption of 0.83429. The standard deviation for Perceived Ease of Use, Facilitating condition and Perceived Usefulness is .74847, .72949 and .75997 respectively. The standard deviation on average is manageable since it is near to " 0 " for all the variables.

\subsection{Correlation Analysis}

Table 7. Correlation

\begin{tabular}{|c|c|c|c|c|c|c|}
\hline & & $\begin{array}{c}\text { System_- } \\
\text { Credebility }\end{array}$ & $\begin{array}{c}\text { Percieved_ } \\
\text { Ease_Of_Use }\end{array}$ & $\begin{array}{l}\text { Facilitating } \\
\text { Conditions }\end{array}$ & $\begin{array}{l}\text { Percieved_ } \\
\text { Usefulness }\end{array}$ & $\begin{array}{c}\text { User_ } \\
\text { Adoption }\end{array}$ \\
\hline \multirow{4}{*}{ System_Credebility } & Pearson Correlation & 1 & $.626^{* *}$ & $.473^{* *}$ & $.578^{* *}$ & $.569^{* *}$ \\
\hline & Sig. (2-tailed) & & .000 & .000 & .000 & .000 \\
\hline & $\mathrm{N}$ & 254 & 254 & 254 & 254 & 254 \\
\hline & Pearson Correlation & $.626^{* *}$ & 1 & $.365^{* *}$ & $.604^{* *}$ & $.541^{* *}$ \\
\hline \multirow{3}{*}{ Percieved_Ease_Of_Use } & Sig. (2-tailed) & .000 & & .000 & .000 & .000 \\
\hline & $\mathrm{N}$ & 254 & 254 & 254 & 254 & 254 \\
\hline & Pearson Correlation & $.473^{* *}$ & $.365^{* *}$ & 1 & $.509^{* *}$ & $.455^{* *}$ \\
\hline \multirow[t]{3}{*}{ Facilitating_Conditions } & Sig. (2-tailed) & .000 & .000 & & .000 & .000 \\
\hline & $\mathrm{N}$ & 254 & 254 & 254 & 254 & 254 \\
\hline & Pearson Correlation & $.578^{* *}$ & $.604^{* *}$ & $.509^{* *}$ & 1 & $.483^{* *}$ \\
\hline \multirow[t]{3}{*}{ Percieved_Usefulness } & Sig. (2-tailed) & .000 & .000 & .000 & & .000 \\
\hline & $\mathrm{N}$ & 254 & 254 & 254 & 282 & 282 \\
\hline & Pearson Correlation & $.569^{* *}$ & $.541^{* *}$ & $.455^{* *}$ & $.483^{* *}$ & 1 \\
\hline \multirow[t]{2}{*}{ User_Adoption } & Sig. (2-tailed) & .000 & .000 & .000 & .000 & \\
\hline & $\mathrm{N}$ & 254 & 254 & 254 & 282 & 282 \\
\hline
\end{tabular}

**. Correlation is significant at the 0.01 level (2-tailed).

Refer Table 7. Correlation determines the relation between two variables. The relation to be measured in this survey is of a dependent variable and independent variables. The independent variables are Perceived Usefulness, Perceived Ease of Use, System Credibility and Facilitating Conditions. This research 
is measuring the impact of these independent variables of the dependent variable which is User Adoption of E-Payment system in Hyderabad.

The relationship between System Credibility and User Adoption is positive and strong. The value of correlation is 0.569 which is significant. Thus, user Adoption has a strong and positive correlation with System Credibility. Changes in one variable will have a positive change in another variable too.

Perceived Ease of Use has a positive and signification relation with User Adoption. The value of correlation is 0.541 which is significant and a strong relationship but not as strong as the relationship of System Credibility and Users Adoption of E-Payment. Changes in one variable will have a positive change in the other variable too.

Facilitating Conditions has a positive and signification relation with User Adoption. The value of correlation is 0.455 which is significant and a strong relationship but not as strong as the relationship of System Credibility and Users Adoption of E-Payment. Changes in one variable will have a positive change in the other variable too.

Perceived Usefulness has a positive and signification relation with User Adoption. The value of correlation is 0.483 which is significant and a strong relationship but not as strong as the relationship of System Credibility and Users Adoption of E-Payment. Changes in one variable will have a positive change in the other variable too.

\subsection{Regression Analysis}

Table 8. Model Summary

\begin{tabular}{|c|c|c|c|c|}
\hline Model & $\mathrm{R}$ & R Square & Adjusted R Square & Std. Error of the Estimate \\
\hline 1 & $.652^{\mathrm{a}}$ & .425 & .416 & .65036 \\
\hline
\end{tabular}

a. Predictors: (Constant), Percieved_Usefulness, Facilitating_Conditions, Percieved_Ease_Of_Use, System_Credebility

Refer Table 11. The model summary table shows an Rsquare of 0.425 that is $42.5 \%$ and adjusted $\mathrm{R}$ sqaure of 0.416 that is $41.6 \%$. This means that there is a probability of almost $41.6 \%$ that changes in the dependent variable are because of the independent variables and the rest $59 \%$ are because of unexplained factors.

Table 9. ANOVA

\begin{tabular}{|ll|l|l|l|l|l|}
\hline & Model & Sum of Squares & Df & Mean Square & F & Sig. \\
\hline \multirow{2}{*}{1} & Regression & 77.839 & 4 & 19.460 & 46.008 & $.000^{\mathrm{b}}$ \\
& Residual & 105.318 & 249 & .423 & & \\
& Total & 183.157 & 253 & & & \\
\hline
\end{tabular}

a. Dependent Variable: User_Adoption

b. Predictors: (Constant), Percieved_Usefulness, Facilitating_Conditions, Percieved_Ease_Of_Use, System_Credebility

Refer Table 9.This table denotes that significance is 0.000 this means that model is fit for consideration.

Table 10. Coefficients

\begin{tabular}{|c|c|c|c|c|c|c|}
\hline \multicolumn{2}{|c|}{ Model } & \multicolumn{2}{|c|}{ Unstandardized Coefficients } & $\begin{array}{l}\text { Standardized Coefficients } \\
\text { Beta }\end{array}$ & $\mathrm{T}$ & Sig. \\
\hline \multirow{4}{*}{1} & (Constant) & .074 & .162 & & .460 & .646 \\
\hline & System_Credebility & .336 & .086 & .263 & 3.917 & .000 \\
\hline & Percieved_Ease_Of_Use & .262 & .076 & .231 & 3.464 & .001 \\
\hline & Facilitating_Conditions & .208 & .067 & .178 & 3.089 & .002 \\
\hline
\end{tabular}

a. Dependent Variable: User_Adoption 
The result shows that most of the people are aware about E-Payment system in Hyderabad. And by reviewing literature and using UTAUT theory and TAM Model it is to identify that the reasons for lack of adoption of E-Payment system are Perceived Usefulness, Perceived Ease of Use, Facilitating Conditions and System Credibility. The correlation shows that if system is credible then customers have no worries to adopt E-Payment system and according to results, Perceived Ease of Use, Facilitating Conditions and System Credibility has an impact on Adoption of E-Payment system but Perceived usefulness has less impact on it .

\section{Recommendation and Future Work}

In future, research can be done by selecting a larger sample size representing the whole Pakistan. This would help us better evaluate the factors which are more important and have significant impact on the usage of E-Payment. An additional area of future research can be by duplicating the current research for another country and then show a comparative analysis of the two countries to show differences such a developed and developing country E-Payment usage.

\section{Conclusion}

The purpose of the study was to achieve an understanding of customers' knowledge or awareness regarding E-Payment system and the reason behind slow adoption of E-Payment system in Hyderabad. Structure established for the research anticipated that User adoption of E-Payment system is influenced by perceived usefulness, perceived ease of use, facilitating conditions and system credibility. This study shows that most of the people are aware about E-Payment system as they uses E-payment system, satisfied from E-payment system. And By using UTAUT and TAM model this study identifies that perceived ease of use, perceived usefulness, system credibility and facilitating conditions are main reasons behind slow adoption of E-Payment system.

\section{References}

Ahmed, U., Zin, M. L. M., \& Majid, A. H. A. (2016). Impact of Intention and Technology Awareness on Transport Industry's E-service: Evidence from an Emerging Economy. 산경연구논집 (IJIDB), 7(3), 13-18.

Masihuddin, M., Khan, B. U. I., Mattoo, M. M. U. I., \& Olanrewaju, R. F. (2017). A survey on e-payment systems: elements, adoption, architecture, challenges and security concepts. Indian Journal of Science and Technology, 10(20), 1-19.

Oney, E., Guven, G. O., \& Rizvi, W. H. (2017). The determinants of electronic payment systems usage from consumers' perspective. Economic research-Ekonomska istraživanja, 30(1), 394-415.

Tarhini, A., El-Masri, M., Ali, M., \& Serrano, A. (2016). Extending the UTAUT model to understand the customers' acceptance and use of internet banking in Lebanon: A structural equation modeling approach. Information Technology \& People, 29(4), 830-849.

Durodolu, O. O. (2016). Technology acceptance model as a predictor of using information system'to acquire information literacy skills. Library Philosophy and Practice.

Urs, B. A. (2015). Security issues and solutions in e-payment systems. Fiat Iustitia, (1), 172-179.

Williams, M. D., Rana, N. P., \& Dwivedi, Y. K. (2015). The unified theory of acceptance and use of technology (UTAUT): a literature review. Journal of Enterprise Information Management, 28(3), 443-488

P. Aigbe, J. Akpojaro, Analysis of Security Issues in Electronic Payment Systems, International Journal of Computer Applications Volume 108 - No. 10, December 2014;

Rachna, P. S. (2013). Issues and challenges of Electronic Payment System. Journal of.

Zokaee, S., Ebrahimi, S. B., \& Ghazizadeh, M. (2012). Electronic payment systems evaluation: a case study in iran. Information Management and Business Review, 4(3), 120.

Zhou, T., Lu, Y., \& Wang, B. (2010). Integrating TTF and UTAUT to explain mobile banking user adoption. Computers in human behavior, 26(4), 760-767 
AbuShanab, E., Pearson, J. M., \& Setterstrom, A. J. (2010). Internet banking and customers' acceptance in Jordan: the unified model's perspective. Communications of the Association for information systems, 26(1), 23.

Irick, M. L. (2008). Task-technology fit and information systems effectiveness. Journal of Knowledge Management Practice, 9(3), 1-5.

Mehmood, N., Shah, F., Azhar, M., \& Rasheed, A. (2014). The Factors Effecting E-banking Usage in Pakistan. Journal of Management Information System and E-commerce, 1(1), 57-94.

Fatonah, S., Yulandari, A., \& Wibowo, F. W. (2018, December). A Review of E-Payment System in E-Commerce. In Journal of Physics: Conference Series (Vol. 1140, No. 1, p. 012033). IOP Publishing. 